\title{
Competency and constraints of higher education and research institutions for rural transformation in the Amhara region, Ethiopia
}

\author{
Getachew Alemayehu ${ }^{1 *}$, Sisay Yehuala ${ }^{2}$, Yonas Worku ${ }^{3}$, Zerihun Nigussie ${ }^{4}$, \\ Girmachew Seraw ${ }^{4}$ \\ ${ }^{1}$ Department of Plant Science, College of Agriculture and Environmental Science, Bahir-Dar University, Bahir Dar, Ethiopia; \\ *Corresponding Author: getachew.64@gmail.com \\ ${ }^{2}$ Department of Rural Development and Agricultural Extension, Faculty of Agriculture, Gondar University, Gondar, Ethiopia \\ ${ }^{3}$ North Gondar Research Centre, Amhara Region Agricultural Research Institute, Gondar, Ethiopia \\ ${ }^{4}$ Department of Rural Development, College of Agriculture and Environmental Science, Bahir Dar University, Bahir Dar, Ethiopia
}

Received 13 March 2012; revised 17 April 2012; accepted 6 May 2012

\section{ABSTRACT}

Ethiopia is an agrarian country and agriculture is the backbone of its economy. Consequently, the government of Ethiopia has devised Agricultural Development Led Industrialization (ADLI) as the country's overall economic development policy. For the last 15 years, public investment towards the expansion of higher education, research and extension in agriculture has been so enormous. In reality, however, these higher education and research institutions were not sufficiently responsive to rural transformation. Thus, to evaluate the role of higher education and research institutions in stimulating rural transformation and to identify main training constraints accountable for their poor performances in institutional learning and rural transformation is of paramount importance. To this effect focus group discussions and key informant interviews were conducted. Stratified and purposive sampling technique was dominantly employed during the survey studies. The result of the study has shown that higher education and research institutions were less responsive to address the actual problems of small-scale farmers and they were limited by a number of constraints/ challenges to address the actual problems of farmers. The major constraints were, to list some, limited involvement in research and extension works by the university staff, students limited practical attachments of the training programmes with farming communities, limited infrastructures and facilities and limited availability of contextualized learning resources. In addressing the aforesaid constraints/challenges, the uni- versity staff should proportionally allocate time in the research and extension activities on top of practical teaching supported by local research results and experience; involving students on practical attachments both in their academic and vacation time; giving emphasis on basic training preparation like fulfilling libraries, laboratories, demonstration fields and transportation facilities; and lastly to revise the existing curriculum in to the direction of solving the real problems of the Amhara region then the country Ethiopia.

Keywords: Rural Transformation; Higher Education; Training Constraints; Competency

\section{INTRODUCTION}

Ethiopia is an agrarian country and agriculture is the backbone of its economy. Agriculture is thus believed to be the major source of the country's economic growth and its development is expected to adequately drive the process of industrialization. Because of this fact, the government of Ethiopia has devised Agricultural Development Led Industrialization (ADLI) as the country's overall economic development policy and the country has been investing appreciably towards agricultural growth. Particularly for the last 15 years, public investment towards the expansion of higher education, research and extension in agriculture and natural resource management has been so enormous. These higher education and research institutions are expected in turn to play a great role in stimulating rural transformation. In reality, however, they are not sufficiently responsive to rural transformation especially addressing problems and priorities 
of resource poor small-scale farmers.

Higher education and research institutions, notably Bahir Dar and Gondar Universities and ARARI which are of the interest of this particular project, are short of the essential human and institutional capacities to conceptually and methodologically address rural transformation through knowledge generation, training and communication of research findings that reach deep into rural communities. By and large these institutions undertake disciplinary trainings and/or distant researches, whereas agriculture in Amhara region as well as in the country is mostly run by small-scale farmers who manage various agricultural practices altogether in less than a hectare of land under diverse conditions. This calls for responsive training and research that addresses diversified farmers' priority constraints.

Higher education institutions in Ethiopia, along with other institutions in the society, are intimately involved in the transformation of the society and have to make hard political and economic choices. They too are characterized by similar struggles as exist in the broader society as social forces vie for pre-eminence. As educators within higher education we do not work in isolated national contexts [1].

A systemic awareness of the interconnections between the macro environment, the meso organizational structural context and the micro cognitive and affective learning interaction is significant. A lifelong learning framework forces our gaze both inwards towards individual and organizational learning and outwards towards relationships in the broader society [2]. The quality of organizational learning internally will have major implications for the institution's ability to function in new ways externally. Not only does there need to be recognition of the multiple layers at which the characteristics come into play, but the ability of organizations to function internally as learning organizations has major implications for their competence to function as flexible, collaborative networks, externally. We need to also come to the realization that individual programmes, grounded in a given development context or learning framework, cannot exist in an "alien” environment and need the support of an enabling system.

Enabling structures and supporting mechanisms are essential. HEI programmes geared to developing development professionals need to be flexible in terms of their entry requirements, financing, delivery mechanisms and their curricula. To establish this requires cooperation both across and within the institution, also with the national or regional higher education authorities [3].

HEIs are increasingly seen as part of a matrix of interlinked agencies that are concerned with social and economic development within their local, regional or national contexts. The need for networking both within the institutions and across institutions of civil society, the economy and government is being emphasized as the recognition of strong local integration is seen as complementing abilities to work effectively at global levels. The balancing of the interests of HEIs, employers and learners is an ongoing task, necessitating continuing dialogue, review, addressing anticipated future needs and changes as well as current contexts.

The objectives of the study were therefore:

1) To evaluate the role of higher education and research institutions in stimulating rural transformation;

2) To identify main training constraints accountable for poor performances of higher education and research institutions in institutional learning and rural transformation.

\section{RESEARCH METHODS}

Desk study was carried out to get background and status of higher education and research institutions of Amhara region/Ethiopia in line with their responsiveness to rural transformation. Furthermore, survey studies were conducted to collect primary information from focus group discussions and key informant interviews. Main stakeholders were primarily identified and segregated into four and eight groups for focus group discussions and key informant interviews, respectively (Table 1). Checklists and semi-structured questionnaires were developed for respective groups of discussants and respondents.

Stratified and purposive sampling technique was dominantly employed during the survey studies. Bahir Dar and Gondar Universities were purposively selected among higher education institutions available in Amhara Region and only agriculture related faculties and departments were used for the study. Heads and vice heads of the selected departments, faculties and universities were almost totally taken as respondents. Instructors and senior students of the selected departments were randomly given the questionnaires to respond. Almost all research directors, programme leaders and researchers of ARARI at head quarter office and Gondar Agricultural Research Centre were purposively used for the study.

Hierarchal purposive sampling was applied to select heads and agricultural experts at regional, zone and district offices of agricultural extension and related sectors including irrigation, land administration and use, food security and disaster risk reduction, and cooperative promotion. All heads and technical departments' heads of these sector offices were tried to use for the study. Unless their number per department was more than 5 , questionnaires were given to almost all agricultural experts of the sector offices mentioned above. In case of exceeding their number greater than 5 in a department, the experts 
Table 1. Groups of stakeholders used for focus group discussions and key informant interviews.

\begin{tabular}{|c|c|c|c|c|}
\hline No. & Focus groups & Main stakeholders & Informant groups & Samples \\
\hline \multirow{3}{*}{1} & \multirow{3}{*}{ Higher education institutions } & \multirow{3}{*}{ - Bahir Dar University } & 1. University heads & 18 \\
\hline & & & 2. Instructors & 36 \\
\hline & & & 3. Students & 88 \\
\hline \multirow{2}{*}{2} & \multirow{2}{*}{ Research institutions } & \multirow{2}{*}{$\begin{array}{l}\text { - } \quad \text { ARARI head quarter } \\
\text { - Gondar Research Centre }\end{array}$} & 4. Research heads & 11 \\
\hline & & & 5. Researchers & 25 \\
\hline \multirow{2}{*}{3} & \multirow{2}{*}{ Employing organizations } & $\begin{array}{l}\text { - Extension and related offices } \\
\text { - } \quad \text { District and village cabinets }\end{array}$ & 6. Employers (heads) & 51 \\
\hline & & $\begin{array}{ll}\bullet & \text { NGOs } \\
- & \text { Privates }\end{array}$ & 7. Employee (alumni) & 127 \\
\hline \multirow[t]{2}{*}{4} & Farmers & $\begin{array}{l}\text { - Farmers } \\
\text { - Farmers associations }\end{array}$ & 8. Farmers & 62 \\
\hline & Total & & & 418 \\
\hline
\end{tabular}

of that specific department was selected randomly.

The project was implemented in Amhara region specifically in north Gondar zone. For that reason, Amhara regional and north Gondar zone offices of these sectors in Bahir Dar and Gondar respectively were selected purposively. Chilga, Dabat and Debark "Woredas" were selected for district level survey studies, while the three selected watersheds of the project namely Wujiraba, Godinge and Mezega are found in these "Woreda", respectively. All development agents (DAs) working in the three selected watersheds were used for the study, whereas farmers in the selected watersheds and in similar gender and age groups were selected randomly.

\section{RESULTS AND DISCUSSION}

\subsection{Current Competency Status for Rural Transformation}

Stakeholders in the focus group discussions of the study strongly expressed that higher education and research institutions are less responsive to address the actual problems of small-scale farmers. In key informant interviews, however, there was variation among different stakeholders in responding to a perception question whether higher education and research institutions are responsive to address the actual problems of small-scale farmers or not. Except university heads, employers and farmers, the majority of respondents including instructors, students, researchers and research heads replied positive for the current responsiveness of higher education and research institutions to transform small scale farmers who run complex activities under diverse conditions rural transformation (Figure 1).

Students were also asked to express their feeling whether the current training program is adequately preparing them for their future career or not, and most of them (61.45\%) responded affirmatively (Figure 2). Similar perception question was also forwarded to the alumni (employees) of different organizations if the university/college fully prepared them for their current assignments and $62.4 \%$ of them responded positively (Figure 2).

Contrary to instructors, students and research staff, $50 \%$ of university heads responded negatively that higher education and research institutions are not responsive to rural transformation (Figure 1). Likewise, most eemployers (70\%) of different governmental and non-governmental organizations responded negatively for the capacity of their newly recruited agricultural experts to facilitate rural transformation and address farmers' problems effectively (Figure 3). Farmers also verified that higher education and research institutions are the least frequently communicated organizations by farmers (Table 2).

The competency of a training or research programme can be also measured by the extent of consulting farmers for their indigenous knowledge. Hence, farmers' opinion was assessed for the extent of consultation to their indigenous knowledge by staffs of different organizations, and the results clearly revealed that staffs of higher education and research institutions almost never consulted farmers (Table 3). Most respondent farmers (80.6\%) in the Wujiraba, Godinge and Mezega watersheds also expressed that they don't get all necessary extension services at the spot (Figure 4).

\subsection{Constraints/Challenges for Their Low Rural Transformation Competency}

\section{University Staff Assessment}

It was expected that higher education and research institutions in the region are not able to address the actual 


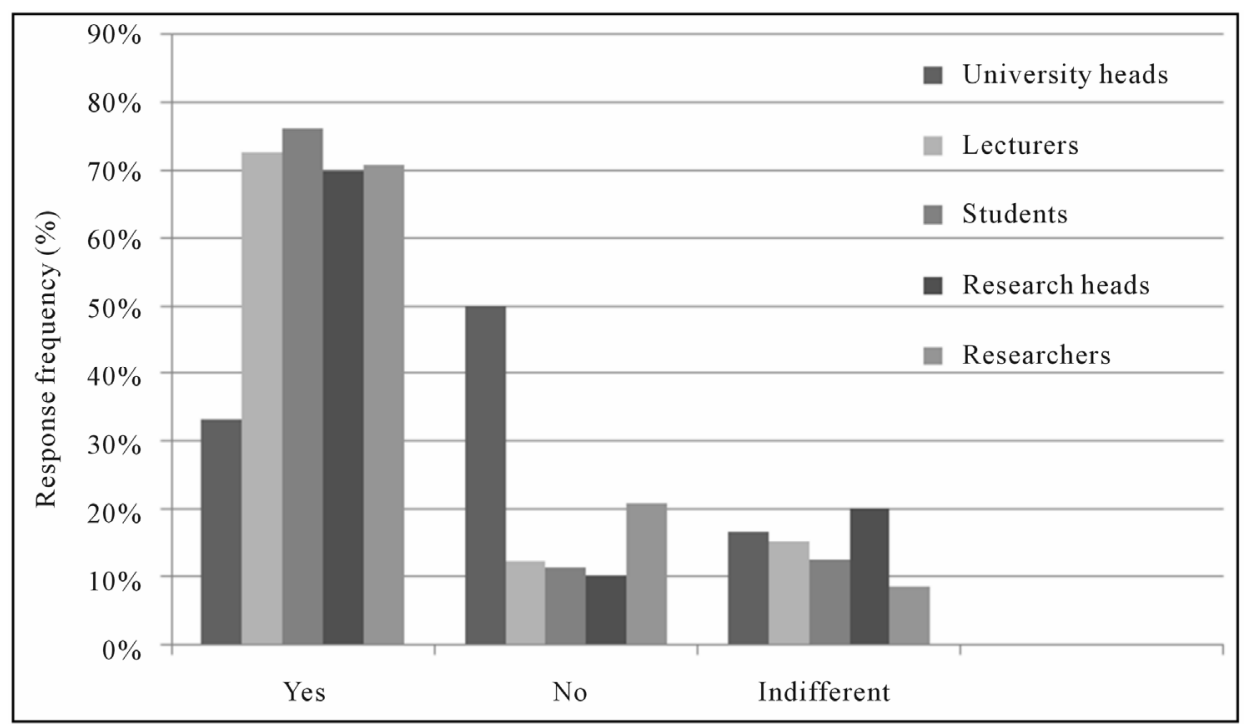

Figure 1. Responses of university and research staffs on their responsiveness to addressing smallscale farmers problem.

Table 2. Responses of farmers on sources of agricultural information and frequency of contact to farmers.

\begin{tabular}{|c|c|c|c|c|c|}
\hline \multirow{2}{*}{ Organization } & \multicolumn{5}{|c|}{ Responses of farmers (frequency) } \\
\hline & Never 1 & Sometimes 2 & Always 3 & Mean & Rank \\
\hline Ministry of agriculture extension offices & 4 & 28 & 30 & 2.42 & 2 \\
\hline Environmental protection offices & 23 & 32 & 5 & 1.70 & 4 \\
\hline University & 50 & 9 & & 1.15 & 7 \\
\hline Technical colleges & 58 & 1 & & 1.02 & 9 \\
\hline NGOs & 23 & 27 & 12 & 1.82 & 3 \\
\hline Research centers & 35 & 23 & 1 & 1.42 & 5 \\
\hline Regional research organizations & 56 & 3 & & 1.05 & 8 \\
\hline National and international research organizations & 48 & 10 & 2 & 1.23 & 6 \\
\hline Other farmers & 7 & 12 & 40 & 2.56 & 1 \\
\hline Total frequency & 304 & 145 & 90 & & \\
\hline Percentage & $56.4 \%$ & $26.9 \%$ & $16.7 \%$ & & \\
\hline
\end{tabular}
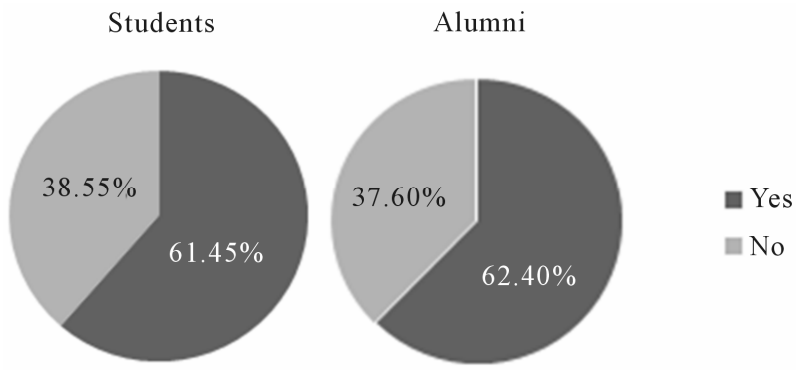

Figure 2. Responses of students and alumni (\%) on the adequateness of universities/colleges and their current training programmes to prepare them for their future career or current assignments. problems of farmers for rural transformation due to some limitations. According to the result of the study, about $41.32 \%$ and $29.86 \%$ of the university head respondents agreed and strongly agreed respectively with the suggested constraints/challenges that are limiting the performance of their institutions (Figure 5). This result was also in harmony with the responses of lecturers, about $46.33 \%$ and $26.2 \%$ of them agreed and strongly agreed respectively with listed constraints as limiting factors for addressing farmers' problems and priorities (Figure 6).

Among the constraints/challenges listed to the respondents, as indicated by the response average in the analysis, the heads group perceived that "Limited practical 


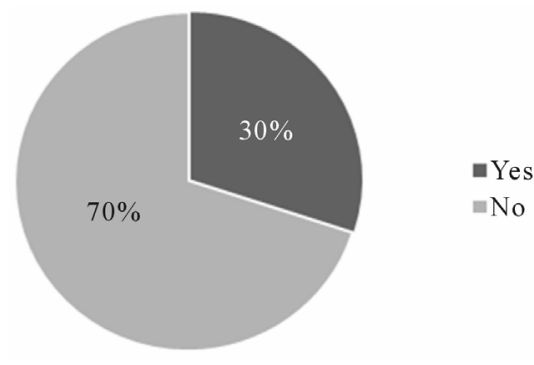

Figure 3. Responses of employers on the capacity of newly recruited agricultural experts to facilitate rural transformation and address farmers' problems effectively.

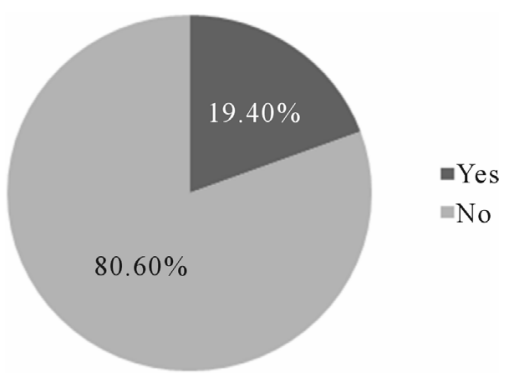

Figure 4. Responses of farmers on whether or not they get all necessary extension services at the spot.

attachments of the training programs with farming communities" is the prior constraint of the institution which was also supported by instructors group that was rated second among the different constraints/challenges. On the other hand "limited infrastructure and facilities like classrooms, libraries, laboratories, demonstration fields, transportation facilities etc." are the most important challenges which were rated first by instructors with a mean response value of 4.46 that is close to the value of agreement and a strong agreement (Table 5). This constraint was also rated second by the group of university heads with a mean response value of 4.06 (Table 4).
From the different constraints/challenges listed in the questionnaire, "limited availability of contextualized learning resources" and "limited opportunities to give practical based-trainings" were perceived by university heads as the second most important constraints. Respondents of university heads ranked "limited consultation of stakeholders in tertiary level agricultural curriculum review and development" with a mean response value of 4.00 as the third main constraints of their institutions. During the study it was generally observed from the perception of university staffs that higher learning institutions are limited by a number of constraints/challenges to address the actual problems of farmers and to be effective development partner playing a great role in stimulating the rural transformation.

From the survey result, perception of some instructors indicated that among the constraints listed to them with a response average value of less 3.5 and greater than 3.0 means a neutral idea to the constraints which means they did not neither agree nor disagree to the suggested constraints of the institutions (Table 5). Accordingly, "the disciplinary nature of the training approach that fails to address the actual problems of farmers" and "high staff turnover" were not perceived by instructors as main constraints of higher education institutions. The latter was not also considered by the head groups as critical constraint (Table 4). On the former one, however, university heads were indifferent from instructors and they rated it as the fifth main constraint with a response average value of 3.89 .

On top of teaching, instructors of universities are expected to be involved actively in research and extension activities. Their limited involvement in research and extension works is generally considered as the main constraint of universities limiting their training quality. The results of the present assessment confirmed this fact that the involvement of university instructors in research and extension service is very limited (Table 6). Out of 36

Table 3. Responses of farmers on the extent of being consulted by staffs of different organizations for their indigenous knowledge.

\begin{tabular}{|c|c|c|c|c|c|}
\hline \multirow{2}{*}{ Organization } & \multicolumn{5}{|c|}{ Responses of farmers (frequency) } \\
\hline & Never 1 & Sometimes 2 & Always 3 & Mean & Rank \\
\hline Training and teaching staff of higher education & 53 & 8 & 1 & 1.16 & 6 \\
\hline Researchers & 40 & 19 & 2 & 1.38 & 5 \\
\hline Extension workers & 7 & 31 & 24 & 2.27 & 1 \\
\hline NGOs officers & 22 & 28 & 12 & 1.84 & 2 \\
\hline Environmental officers & 27 & 32 & 3 & 1.61 & 3 \\
\hline Cooperative promotion experts & 34 & 19 & 9 & 1.60 & 4 \\
\hline Total frequency & 183 & 137 & 51 & & \\
\hline Percentage & $49.33 \%$ & $36.93 \%$ & $13.75 \%$ & & \\
\hline
\end{tabular}




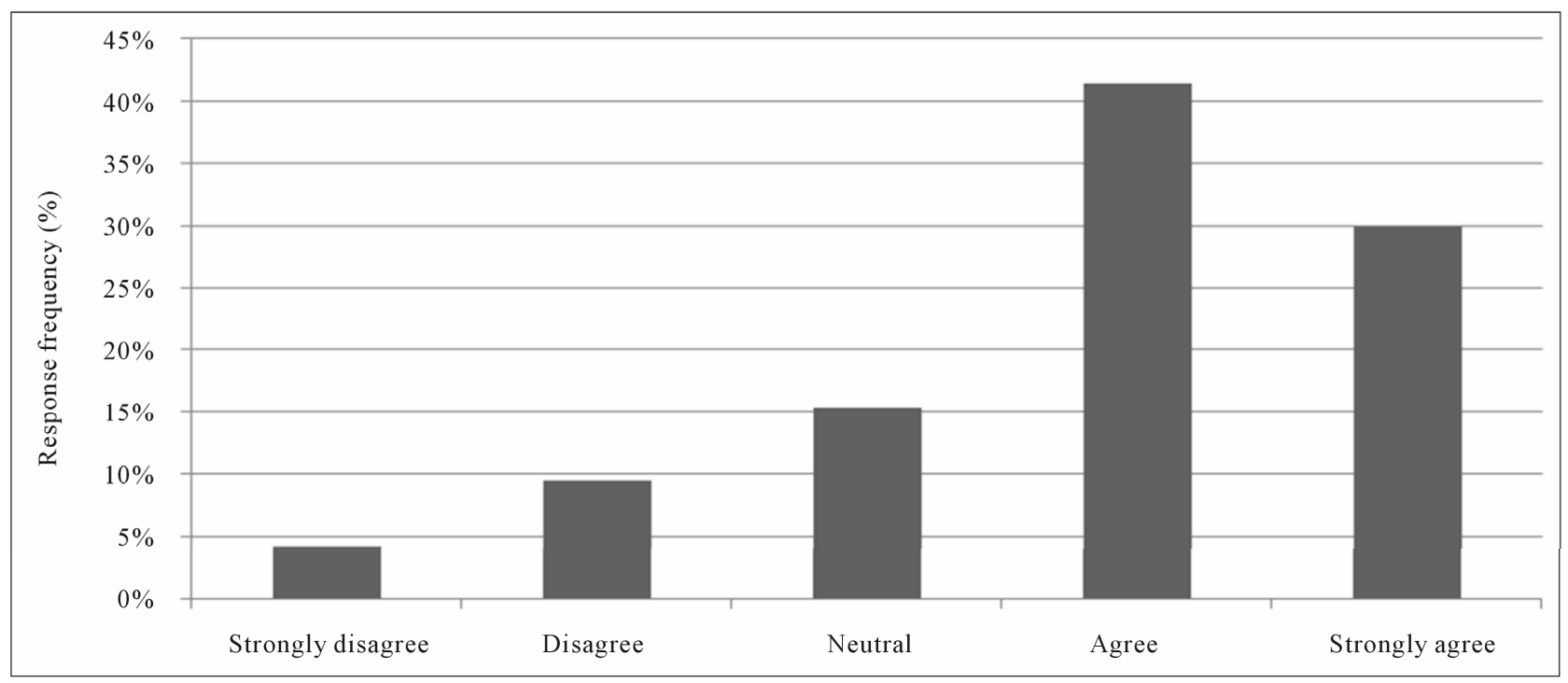

Figure 5. Response of university heads on the different constraints/challenges of higher education institutions.

Table 4. Constraints/Challenges of higher education institutions for their training programmes as rated by university heads.

\begin{tabular}{|c|c|c|c|c|c|c|c|}
\hline Constraints/Challenges & SD (1) & D (2) & $\mathbf{N}(3)$ & A (4) & SA (5) & Mean & Rank \\
\hline Disciplinary training programs of the universities & 1 & 1 & 2 & 9 & 5 & 3.89 & 5 \\
\hline Disciplinary training approach is limited in addressing the actual problems of farmers & 1 & 1 & 2 & 9 & 5 & 3.89 & 5 \\
\hline Limited availability of contextualized learning resources & & 2 & 1 & 9 & 6 & 4.06 & 2 \\
\hline Limited opportunities to give practical based-trainings & 1 & 0 & 2 & 9 & 6 & 4.06 & 2 \\
\hline $\begin{array}{l}\text { Limited consultation of stakeholders in tertiary level agricultural curriculum review } \\
\text { and development }\end{array}$ & 0 & 3 & 1 & 7 & 7 & 4.00 & 3 \\
\hline Lack of inter-disciplinary linkage & 0 & 1 & 2 & 12 & 3 & 3.94 & 4 \\
\hline Lack of institutional linkage & 0 & 2 & 2 & 11 & 3 & 3.83 & 6 \\
\hline Limited experience of instructors & 1 & 3 & 3 & 8 & 3 & 3.50 & 8 \\
\hline Limited knowledge of the local realities & 1 & 1 & 4 & 6 & 6 & 3.83 & 6 \\
\hline $\begin{array}{l}\text { Limited experiences insights and priorities of farmers and rural communities } \\
\text { diffusion into the training programs of higher education }\end{array}$ & 1 & 1 & 6 & 2 & 8 & 3.83 & 6 \\
\hline Limited practical attachments of the training programs with farming communities & & 1 & 2 & 8 & 7 & 4.17 & 1 \\
\hline Limited research and community services & 1 & 2 & 1 & 7 & 7 & 3.94 & 4 \\
\hline High staff turnover & & 5 & 6 & 4 & 3 & 3.28 & 10 \\
\hline Lack of motivation of staff & 1 & 3 & 4 & 7 & 3 & 3.44 & 9 \\
\hline Limited budget & 2 & 1 & 4 & 6 & 5 & 3.61 & 7 \\
\hline Limited infrastructure and facilities & 2 & & 2 & 5 & 9 & 4.06 & 2 \\
\hline Total frequency & 12 & 27 & 44 & 119 & 86 & & \\
\hline
\end{tabular}

SD = Strongly Disagree; D = Disagree; N = Neutral; A = Agree; SA = Strongly Agree.

sampled instructors nine (25\%) of them did not participate in any research activities, while the other 10 (28\%) of them spent only up to $10 \%$ of their time for reach works (Table 6). Similarly, the majority of the respondent instructors (66.6\%) did not participate in any extension activities (Table 6). The present results showed that 


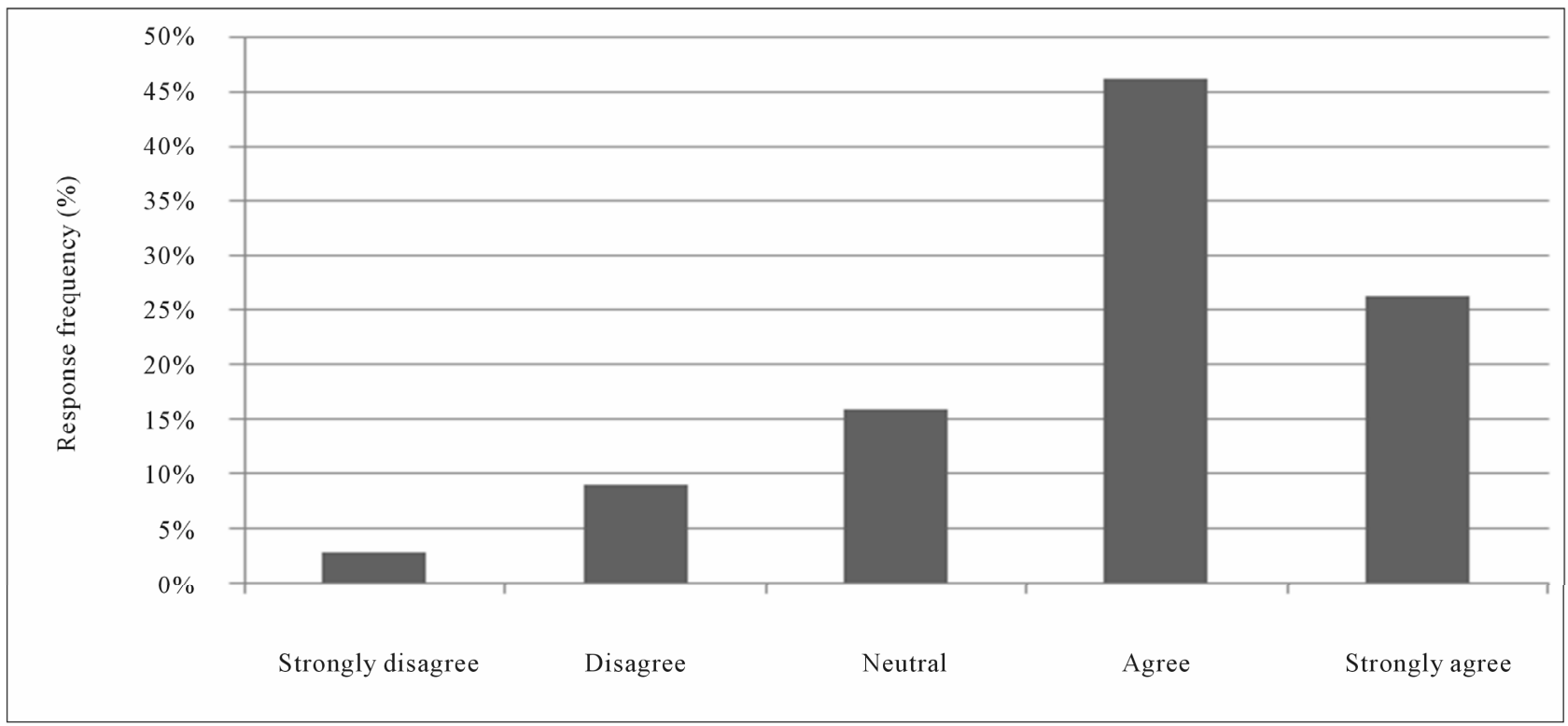

Figure 6. Response of instructors on different constraints/challenges of higher education institutions.

Table 5. Constraints/Challenges of higher learning institutions for their training programmes as rated by university instructors.

\begin{tabular}{|c|c|c|c|c|c|c|c|}
\hline Constraints/Challenges & SD (1) & D (2) & $\mathbf{N}(3)$ & A (4) & SA (5) & Mean & Rank \\
\hline Disciplinary training programs of the universities & 2 & 2 & 8 & 19 & 4 & 3.60 & 11 \\
\hline Disciplinary training approach is limited in addressing the actual problems of farmers & 3 & 4 & 7 & 14 & 6 & 3.47 & 14 \\
\hline Limited availability of contextualized learning resources & & 3 & 4 & 21 & 7 & 3.91 & 8 \\
\hline Limited opportunities to give practical based-trainings & & 2 & 4 & 13 & 15 & 4.21 & 4 \\
\hline $\begin{array}{l}\text { Limited consultation of stakeholders in tertiary level agricultural curriculum review } \\
\text { and development }\end{array}$ & & 1 & 6 & 23 & 5 & 3.91 & 8 \\
\hline Lack of inter-disciplinary linkage & & 3 & 4 & 18 & 10 & 4.00 & 7 \\
\hline Lack of institutional linkage & & 2 & 3 & 14 & 16 & 4.26 & 3 \\
\hline Limited experience of instructors & 2 & 2 & 11 & 13 & 7 & 3.60 & 11 \\
\hline Limited knowledge of the local realities & 2 & 4 & 4 & 21 & 3 & 3.56 & 12 \\
\hline $\begin{array}{l}\text { Limited experiences insights and priorities of farmers and rural communities diffusion } \\
\text { into the training programs of higher education }\end{array}$ & 1 & 3 & 3 & 19 & 8 & 3.88 & 9 \\
\hline Limited practical attachments of the training programs with farming communities & & & 2 & 20 & 13 & 4.31 & 2 \\
\hline Limited research and community services & & 1 & 2 & 23 & 9 & 4.14 & 5 \\
\hline High staff turnover & 2 & 7 & 16 & 8 & 2 & 3.03 & 15 \\
\hline Lack of motivation of staff & 1 & 8 & 5 & 13 & 8 & 3.54 & 13 \\
\hline Limited budget & 2 & 5 & 4 & 14 & 10 & 3.71 & 9 \\
\hline Limited top management support to instructors & 1 & 6 & 9 & 11 & 8 & 3.54 & 13 \\
\hline Lack reward systems to motivate academic staff & & 3 & 4 & 17 & 11 & 4.03 & 6 \\
\hline Limited infrastructure and facilities & 1 & & 3 & 9 & 22 & 4.46 & 1 \\
\hline Total frequency & 17 & 56 & 99 & 290 & 164 & & \\
\hline
\end{tabular}

SD = Strongly Disagree; D = Disagree; N = Neutral; A = Agree; SA = Strongly Agree. 
Table 6. Working time share (\%) of university instructors for various activities.

\begin{tabular}{|c|c|c|c|c|c|c|}
\hline \multirow{2}{*}{ Activity } & \multicolumn{6}{|c|}{ Responses of instructors for their time spending percentage } \\
\hline & $\mathbf{0 \%}$ & $1 \%-10 \%$ & $11 \%-25 \%$ & $26 \%-50 \%$ & $51 \%-75 \%$ & $>75 \%$ \\
\hline Administration & 1 & 35 & & & & \\
\hline Research & 9 & 10 & 12 & 5 & & \\
\hline Extension service & 24 & 9 & 2 & 1 & & \\
\hline Training & 1 & 2 & 1 & 11 & 8 & 13 \\
\hline Field work & 16 & 16 & 1 & 2 & & 1 \\
\hline Field work supervision & 22 & 12 & 2 & & & \\
\hline
\end{tabular}

university instructors are more involved on theoretical teaching which is not supported with local research results and experiences.

\section{CONCLUSION AND RECOMMENDATION}

Though most instructors, students, alumni and research staffs responded positively to the responsiveness of higher education and research institutions to rural transformation as well as to the adequacy of the current training programmes for the preparation of their career, their primary customers mainly employers and farmers confirmed that higher education and research institutions of Amhara region/Ethiopia are less responsive to rural transformation particularly in addressing constraints and priorities of poor resource small-scale farmers. The positive response of instructors, students, alumni and research staffs might be associated with lack of confidence to challenge their problems. Besides, providing negative response to one's own problems is also uncommon to some people. Thus, it was recommended that university heads, lecturers, students, research heads and researchers should conduct different workshops and meetings to revise and evaluate the responsiveness of higher education and research institutions towards achieving the intended objective. All these stake holders with different ideas should confidentially come together towards a fruitful exercise for defining solution and reach on consensus.

On the other hand, looking in to the assessment of university staff, it was generally observed that higher education and research institutions were limited by a number of constraints/challenges to address the actual problems of farmers as well as to be effective development partner to play a great role in stimulating the rural transformation. The major constraints were, to list some, limited involvement in research and extension works by the university staff, students limited practical attach- ments of the training programmes with farming communities, limited infrastructures and facilities and limited availability of contextualized learning resources. In addressing the aforesaid constraints/challenges, the university staff should proportionally allocate time in the research and extension activities on top of practical teaching supported by local research results and experience; involving students on practical attachments both in their academic and vacation time; giving emphasis also on the management of training including basic training preparation supported by libraries, laboratories, demonstration fields and transportation facilities; and lastly to revise the existing curriculum in to the direction of solving the real problems of the region then the country.

\section{ACKNOWLEDGEMENTS}

The original research results of this paper are derived by the TRANSACT (Strengthening Rural Transformation Competences of Higher Education and Research Institutions in the Amhara Region, Ethiopia) project. This project is funded by the Austrian Development Agency, the operational unit of the Austrian Development Cooperation (ADC), under the frame of APPEAR (Austrian Partnership Programme in Higher Education \& Research for Development). Hence, the authors sincerely acknowledge APPEAR-TRANSACT project for its support.

\section{REFERENCES}

[1] Walters, S. (1999) Lifelong learning within higher education in South Africa: Emancipatory potential? International Review of Education, 45, 575-587. doi:10.1023/A:1003847629351

[2] Volbrecht, T. and Walters, S. (2000) Re-imagining a picture: Higher education in lifelong learning. Adult Education and Development, 55, 271-291.

[3] Bron, A. (2001) Adult education and lifelong learning. Conference on Citizenship, Adult Education and Lifelong Learning, 41, Copenhagen, 4-6 April 2001, 357-361. 


\section{ACRONYMS AND TERMINOLOGIES}

1) Amhara: One of the regions in Ethiopia located in the north western of the country;

2) Gondar: One of the zones in Amhara region located in the north west of it;

3) Bahir Dar: Capital city of Amhara region located in the north western of it;

4) Woreda: District;

5) Chilga, Dabat and Debark: Districts geographically located in north Gondar;

6) Wujiraba, Godinge and Mezega: Name of the three selected watersheds of the project geographically located in the above mentioned three Woredas respectively;

7) ARARI: Amhara Region Agricultural Research Institute;

8) ADLI: Agricultural Development Led Industrialization;

9) DA: Development Agent (Extension worker working with a farmer at a grass root level);

10) NGO: Non Governmental Organization;

11) HEI: Higher Education Institution. 